\title{
A inovação como estratégia nas organizações sustentáveis: 0 programa piloto brasileiro para concessão das patentes verdes
}

Recebido em 20.01.2016. Aprovado em 20.11.2016 Avaliado pelo sistema double blind review

\author{
lara Tonissi Moroni Cutovoi
}

itmoroni@hotmail.com

FGV-EAESP Escola de Administração de Empresas de São Paulo - São Paulo - SP

\begin{abstract}
Resumo
0 presente trabalho relata como a inovação das patentes verdes pode contribuir para a estratégia de sustentabilidade da organização. A importância e relevância deste estudo se justificam devido ao aumento gradativo e interesse das empresas pela inserção de práticas sustentáveis em seus processos, trouxe maior foco para operações verdes, juntamente às demandas legislativas dos governos e à sustentabilidade. Desta forma, existe uma lacuna na literatura de estudos que tratem das diretrizes e abordagens de programas e legislações vigentes neste aspecto. $O$ objetivo principal é analisar a inovação trazida por tais patentes e sua relação com a sustentabilidade, referente às competências e implantação de suas estratégias nos níveis operacional, tático e estratégico. Discute-se também a economia circular, e quais as atuais propostas inovadoras, que corroborem para o planejamento. Um dos aspectos importantes para esta economia é a inovação, sendo necessário seu incentivo, de forma a promover um novo crescimento econômico, fundamentado na aplicação eficiente dos recursos e dos ativos ambientais. Em vista disso, o intuito é responder à seguinte questão: Como as patentes verdes ajudam na estratégia de inovação das organizações sustentáveis? O programa piloto brasileiro é analisado frente às concessões de Patentes Verdes, lançado pelo INPI (Instituto Nacional da Propriedade Intelectual) do governo brasileiro lançado em 2012, o qual se encontra na prorrogação de sua terceira fase, que se estenderá até 16 de abril de 2016 ou até atingir 500 novas vagas. Metodologicamente, o estudo pode ser considerado como revisão estruturada da literatura, de natureza qualitativa. Por fim, demonstra-se que a patente verde pode servir de instrumento gerador da produção de tecnologias verdes. Sendo que contribui para a economia circular e para a diminuição do tempo de análise das solicitações de patentes verdes, proporcionando maiores incentivos a investimentos e inovações na área ambiental. A conclusão é que existe uma convergência através da maior demanda de exigências ambientais pela sociedade.
\end{abstract}

Palavras-chaves: Patentes. Lei de Inovação Tecnológica (LIT). Inovação e sustentabilidade.

\section{Introdução}

À luz dos autores Canongia, Santos e Zackiewicza (2004) hoje as organizações competitivas possuem como uma das mais importantes características a capacidade de inovar.

O Fórum de Inovação da Escola de Administração de São Paulo da Fundação Getúlio Vargas (FGV/EAESP) define inovação, genericamente considerada, pela seguinte equação: inovação = idéia + implementação + resultado. Desta forma, portanto, apenas existirá uma inovação se houver idéia, se esta for implementada e uma vez em operação traga resultados.

Conforme Schumpeter (1982) o conhecimento produzido responde pelo desenvolvimento quando é utilizado de forma tal que é capaz de gerar inovações. Vale ressaltar também, que o conhecimento produzido alavanca 0 crescimento econômico se for absorvido de forma adequada, e assim este se torna um ativo tão importante que pode gerar ganhos de competitividade FREEMAN (1987). 
Da mesma forma, o desenvolvimento da capacidade de inovar não depende apenas de elementos internos das empresas, há sempre componentes dados pelo ambiente externo e decisões, que precisam ser tomados relativamente a ele. A capacidade de inovar depende também de condições objetivas dadas pela capacidade social de criar conhecimento do ambiente em que se insere a organização, incluindo a existência de competências específicas, de financiamento e de baixos custos de transação. Em outras palavras, da existência de sistemas de inovação bem constituídos (Lundvall, 2001)

Desta forma, a finalidade deste estudo foi esclarecer o que a inovação das patentes verdes contribui para a estratégia de sustentabilidade. Vale ressaltar que tanto estratégia quanto inovação vêm sendo usado de maneira indiscriminada na área da gestão. Assim, considerando a sua importância, falar de estratégia e inovação abre uma discussão entre concepções teóricas, que vão desde as abordagens mais convencionais, até as mais dinâmicas, que entendem que esse processo está associado a fatores culturais, de aprendizagem, política e relações de poder (MINTZBERG; AHSLTRAND; LAMPEL, 1998).

Segundo Bessant e Tidd (2009, p. 27) "o sucesso da inovação parece depender de dois ingredientes principais: recursos e capacidade da organização para geri-los".

Assim, de acordo com o Instituto Inovação (2008), ao levar em consideração que as inovações são capazes de gerar vantagens competitivas a médio e longo prazo, inovar torna-se fator essencial para a sustentabilidade das empresas e dos países no futuro. Obviamente, os benefícios da inovação não se limitam às empresas. Para os países e regiões, as inovações possibilitam o aumento do nível de emprego e renda, além do acesso ao mundo globalizado e suas tecnologias.

A Conferência Rio +20 , denominada de "O futuro que queremos", discute a criticidade da tecnologia e a relevância da promoção da inovação. Sobretudo, propõe aos governos a criação de estruturas que promovam a pesquisa e inovação para o suporte da economia verde no contexto do desenvolvimento sustentável. É enfatizada também, a importância dos direitos de propriedade intelectual e acesso a informação, principalmente no intuito de fomentar, o acesso ao desenvolvimento, transferência e difusão de tecnologias ambientalmente saudáveis.

Desta forma, questiona-se se os conceitos de estratégia e gestão da inovação são compreendidos pelos gestores de empresas, principalmente para trazer mais sustentabilidade.

Portanto, este estudo pretende responder a seguinte questão: como as patentes verdes ajudam na estratégia de inovação das organizações?

$O$ texto está estruturado em cinco seções, incluindo as notas introdutórias. A segunda o referencial teórico. A terceira, o método. A quarta, o programa piloto "Patentes Verdes" e, por fim, a quinta, com as discussões e considerações finais.

\section{Definições de Patente e Patentes Verdes}

Um dos conceitos de patente, refere-se ao registro temporário por meio do qual há a proteção do invento a ser utilizado comercialmente, sendo que nela está o conhecimento humano gerado e registrado para a disseminação da invenção realizada (WIPO, 2010).

Já conforme o INPI (2013) a patente é conceituada como:

(...) uma propriedade temporária, legalmente concedida pelo Estado, sobre uma invenção ou modelo de utilidade. É uma forma de reconhecimento do esforço inventivo e, por isso, garante ao seu proprietário direito exclusivo sobre sua invenção. Por ser um importante e valioso instrumento para proteger e tornar a invenção rentável é preciso depositar o pedido de concessão junto ao Instituto Nacional da Propriedade Industrial (INPI), responsável pela análise do pedido de acordo com as regras da Lei 9.279/96. É bom lembrar que, esta mesma lei determina em seu artigo 10 o que não é considerado invenção nem modelo de utilidade, sendo assim, o que não é passível de ser patenteado. (INPI, 2013). 


\section{A inovação como estratégia nas organizações sustentáveis: 0 programa piloto brasileiro para concessão das patentes verdes}

Faz-se necessário evidenciar, conforme Barbosa (2012) que na definição de patente, é citado que em contrapartida pelo acesso do público ao conhecimento dos pontos essenciais do invento, a lei dá ao titular da patente um direito limitado no tempo, no pressuposto de que é socialmente mais produtiva em tais condições a troca da exclusividade de fato, ou seja, pela exclusividade temporária de direito.

A lei de propriedade intelectual (LPI) - Lei 9.279 de 14/05/96 releva que a patente é proteção do conhecimento feita pelo Estado, através de um título de propriedade temporária sobre uma invenção ou modelo de utilidade. O título é conferido ao inventor ou a quem este ceder seus direitos. Como contraprestação, o titular tem que detalhar com alta suficiência e precisão seu invento ou modelo de utilidade a ser protegido pela patente. 0 direito de exclusividade concedido pelo Estado tem a finalidade de promover o desenvolvimento tecnológico e econômico do País. Os tipos de patentes previstos na Lei de Propriedade Industrial (LPI) brasileira:

1. De invenção (fazer algo novo); vigora por um período de 20 anos;

2. Modelos de utilidade (uma melhoria de produto ou processo existente); vigora por um período de 15 anos . (arts 2 e 40 da Lei de Propriedade Industrial - LPI - 9.279/1996)

Conforme o INPI a legislação brasileira não define invenção, como também acontece na maioria das leis estrangeiras. A invenção é a criação de algo até então inexistente, que resulta da capacidade intelectual do seu autor e que representa uma solução nova para um problema existente, visando um efeito técnico em uma determinada área tecnológica. As invenções podem ser referentes a produtos industriais (compostos, composições, objetos, aparelhos, dispositivos, etc.) e a atividades industriais (processos, métodos, etc.).

Sobretudo o modelo de utilidade, de acordo com o INPI, consiste em um instrumento, utensílio e objeto de uso prático, ou parte deste, que apresente nova forma ou disposição que resulte em melhoria funcional no seu uso ou em sua fabricação. O modelo se refere a um objeto de corpo certo e determinado, não incluindo os sistemas, processos, procedimento ou métodos para obtenção de algum produto. A novidade de um modelo pode decorrer de uma combinação ou na composição do conjunto de elementos conhecidos (kits, pré-moldados, etc.). De acordo com o INPI, as características fundamentais das patentes são:

a) Propriedade limitada temporalmente: Diferentemente de outros sistemas de propriedade, a validade limitada a um determinado período de tempo, permite que após o transcurso desse período a patente caia em domínio público, estando apta para ser usada por toda a sociedade, incentivando o inventor a prosseguir na pesquisa de aperfeiçoamentos, buscando evitar a superação por seus concorrentes.

b) Interesse público na divulgação da informação contida no pedido de patente. $O$ interesse público fica preservado na divulgação da informação, permitindo à sociedade o livre acesso ao conhecimento da matéria objeto da patente. Dessa forma, os concorrentes do inventor podem desenvolver suas pesquisas a partir de um estágio mais avançado do conhecimento, promovendo, assim, o desenvolvimento tecnológico do país.

c) A patente é válida apenas nos países onde foi requerida e concedida a sua proteção. Cada país é soberano para conceder ou não a patente independentemente da decisão em outros países sobre pedidos de patentes correspondentes (art. $4^{\circ}$ bis da "Convenção da União de Paris para Proteção da Propriedade Industrial" - CUP, promulgada através dos decretos n 75.572, de 8 de abril de 1975 e n 635, de 21 de agosto de 1992).

\section{Patentes Verdes}

A importância de um sistema de patentes forte para incentivar 0 investimento em inovação e facilitar 0 licenciamento das tecnologias e a gestão do projeto das patentes verdes. O Instituto Nacional de Patentes Industriais (INPI) com esse novo programa visa estimular a produção e proteção de invenções e estudos relacionados ao ideal de sustentabilidade, conhecido como Patentes Verdes. O programa em questão terá busca como meta a facilitação do processo de proteção da propriedade intelectual na forma de tecnologia verde. INPI (2015) 
A patente verde conceituada consiste em "tecnologias que protegem o meio ambiente" (AGENDA 21. Capítulo 34, p. 409)

O programa "Patente Verdes" tem como objetivo contribuir para as mudanças climáticas globais e visa a acelerar o exame dos pedidos de patentes relacionados a tecnologias voltadas para o meio ambiente (Resoluções PR n0 131/2014 e PR n0145/2015).

Com esta iniciativa, o INPI também possibilita a identificação de novas tecnologias que possam ser rapidamente usadas pela sociedade, estimulando o seu licenciamento e incentivando a inovação no país. O programa piloto teve seu início em 17 de abril de 2012 e encontra-se na prorrogação de sua terceira fase, que se estenderá até 16 de abril de 2016 ou até atingir 500 novas vagas. Na nova ampliação, os pedidos via Tratado de Cooperação em Matéria de Patentes (PCT, na sigla em inglês) poderão participar.

\section{Lei de Inovação Tecnológica - LIT}

A Lei de Inovação Tecnológica - LIT (Lei Federal n. 10.973 de 02.12.2004) estabelece medidas de incentivo à inovação e à pesquisa científica e tecnológica no ambiente produtivo, com vistas à capacitação e ao alcance da autonomia tecnológica e ao desenvolvimento industrial do País, por meio da análise das principais medidas descritas em seu texto.

O ponto positivo desta lei é que ela feita para incentivar novos modelos de parcerias entre setor público e setor privado. Desta forma, essa variedade de relacionamentos, e diversos atores da sociedade, reflete na importância de construir um aprendizado tanto na dimensão das proximidades da comunidade onde a universidade está inserida, quanto na esfera global, e isto não é não é trivial. São instituições com valores e missões distintas. Uma se propõe a formar as novas gerações e difundir o conhecimento, a outra se propõe a apropriar o conhecimento para criar ou ampliar sua participação no mercado. E desta forma, tais características não são homogêneas e isso não significa que não possam interagir.

Nota-se que a Lei de Inovação Tecnológica está dividida em três eixos: primeiro eixo: Estímulo à construção de ambientes especializados e cooperativos de Inovação (art. $3^{\circ}$ ao art. $5^{\circ}$ ). 0 segundo eixo: Estímulo à participação das ICT's no processo de Inovação (art. $6^{\circ}$ ao art. $18^{\circ}$ ). E por fim o terceiro eixo: Estímulo à Inovação nas empresas (art. $19^{\circ}$ ao art. $21^{\circ}$ ).

0 primeiro eixo apontado pela lei de inovação tecnológica, diz respeito aos estímulos à construção de ambientes especializados e cooperativos de inovação. Nesta perspectiva, orienta os termos legais para a interação entre o setor público e o privado a fim de constituir alianças estratégicas e projetos de cooperação envolvendo empresas nacionais, ICT's (Instituição Científica e Tecnológica - ICT: órgão ou entidade da administração pública que tenha por missão institucional, dentre outras, executar atividades de pesquisa básica ou aplicada de caráter científico ou tecnológico) e organizações de direito privado sem fins lucrativos com intuito de realizarem atividades de $\mathrm{P} \& \mathrm{D}$, com a finalidade de alcançarem à geração de produtos e processos inovadores.

No segundo eixo, nota-se o estímulo à gestão da inovação, estabelecendo regimes de comercialização das inovações científicas e tecnológicas. Neste capítulo são disciplinas as bases legais para a participação das ICTs na inovação. 0 art. $6^{\circ}$ da lei facultou a possibilidade de a ICT celebrar contratos de transferência de tecnologia ou de licenciamento para outorga de direito de uso ou de exploração de criação por ela desenvolvida.

São tratadas questões de como a instituição poderá fazer contratos de transferência de tecnologia e licenciamento para exploração comercial das inovações.

No seu terceiro e último eixo, a lei de inovação tecnológica propõe dois dispositivos legais que possuem a finalidade de estimular à inovação de no âmbito das empresas. 0 artigo 19 disciplina os instrumentos nos nortes da inovação na seara do setor produtivo Avalia-se a permissão da utilização de recursos financeiros, humanos e materiais da União para tornar viável a cooperação entre empresas em arranjos pré-competitivos. Faculta-se a utilização, pelas empresas, de laboratórios e equipamentos das instituições científicas e tecnológicas. Institui regime de preferência de compra de bens e serviços para as EBTs de pequeno e médio porte.

\section{Inovação e Sustentabilidade}




\section{A inovação como estratégia nas organizações sustentáveis: 0 programa piloto brasileiro para concessão das patentes verdes}

O termo inovação vem do latim innovare, e significa fazer algo novo. De acordo com Tidd, Bessant e Pavitt (2008), a inovação é um processo de fazer de uma oportunidade uma nova ideia e de colocá-la em uso da maneira mais ampla possível. Sobretudo, em vista disso, a inovação se configura como um processo irreversível incluindo diversas etapas e aspectos financeiros, culturais e organizacionais. Conforme Barbieri e Simantob (2007), a inovação é uma iniciativa, modesta ou revolucionária, que surge como uma novidade para a organização e para o mercado e que, aplicada na prática, traz resultados econômicos para a empresa sejam eles ligados à tecnologia, gestão, processos ou modelo de negócio.

De acordo com Massaini (2015) a inovação põe em prática idéias novas através do uso de novas tecnologias, reciclagem, utilizando menos matérias-primas, pode-se gerar uma produção mais eficiente e limpa, com preservação de recursos naturais, competitividade para as organizações e benefícios para toda a sociedade. KEINERT (2007)

Conforme Barbieri (2007) a organização inovadora introduz novidades de qualquer tipo em bases sistemáticas e colhe os resultados esperados. Já a organização sustentável: simultaneamente eficiente em termos econômicos, respeita a capacidade de suporte do meio ambiente, é instrumento de justiça social, promovendo a inclusão social, proteção às minorias e grupos vulneráveis, equilíbrio entre os gêneros, etc.

Desta forma uma organização inovadora sustentável é a que introduz novidades que atendam as múltiplas dimensões da sustentabilidade em bases sistemáticas e colham resultados positivos para ela, para a sociedade e o meio ambiente BARBIERI (2007).

Conforme Teigland, Fey e Birkinshaw (2000), uma sociedade sustentável depende da presença de sistemas de inovação, que produzam resultados que não prejudicam a sociedade, o que se reflete na realidade das organizações. Para Luiza, Wisniewski, \& Bollmann (2012) a geração de inovação tecnológica pode representar uma estratégia de competitividade pelas empresas, considerando parte do sucesso das organizações é devido à sua capacidade de criar uma vantagem competitiva através da introdução de inovações tecnológicas.

O Manual de Oslo afirma que uma maior conscientização da importância da inovação fez com que ela fosse incluída na agenda política da maioria dos países desenvolvidos, com foco básico em políticas de ciência e tecnologia e aspectos de políticas industriais. O novo pensamento sobre inovação fez surgir a importância dos sistemas e levou a uma abordagem mais integrada da formulação e implantação de políticas ligadas à inovação. OECD (2004)

Para que a sustentabilidade se incorpore efetivamente no desenvolvimento de inovações, é fundamental que 0 sistema nacional de inovação esteja mobilizado para tanto, devendo se adequar a essa nova realidade. BARBIERI et al (2010).

Os modelos de inovação podem ser classificados em dois grandes grupos: inovação fechada e inovação aberta. No modelo tradicional de inovação fechada, Chesbrough (2006) mostra que os projetos estão estruturados na base científica e tecnológica da empresa, passam por uma seleção interna e alguns são descontinuados enquanto outros recebem mais recursos sendo que poucos chegam ao mercado. $O$ autor cita ainda que esses processos são chamados de fechados porque têm somente uma entrada - 0 departamento de P\&D, e uma saída - o mercado. Para Chesbourgh (2006), as empresas que trabalham com inovação fechada estão baseadas na filosofia de que uma inovação de sucesso tem que ser controlada e as empresas devem gerar suas próprias ideias que serão então desenvolvidas, fabricadas, comercializadas e protegidas. As vantagens competitivas são alcançadas com altos investimentos em laboratórios de Pesquisa e Desenvolvimento - P\&D, capital intelectual, incursões de ideias e de tempo de desenvolvimento para se chegar a uma solução inovadora.

Chesbrough (2006) define o conceito de inovação aberta como o uso intencional dos fluxos internos e externos de conhecimento para acelerar a inovação interna e a expansão de mercado para uso externo das inovações. A inovação aberta propõe que os resultados sejam alcançados em atividades como a prospecção, análise e exposição de oportunidades de inovação, usando tanto ideias externas como ideias internas e caminhos 
internos e externos para alcançar o mercado. Conforme ilustrado a seguir na figura 1, é demonstrado os mecanismos de gestão da inovação.

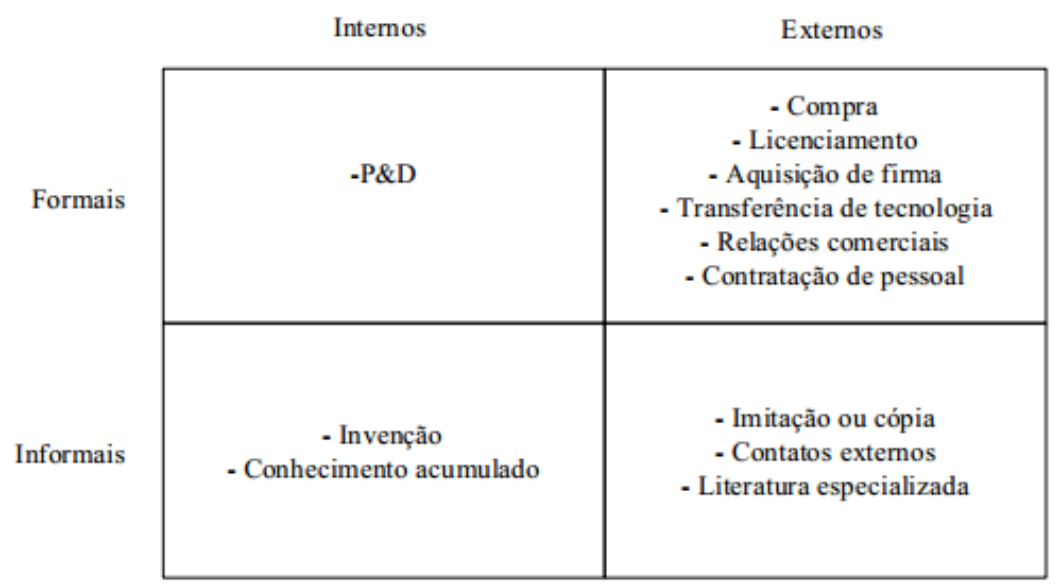

Figura 1: Os mecanismos para inovação.

Fonte: Fonseca \& Kruglianskas (2002).

Assim, a partir de quatro possibilidades cruzadas de difusão da inovação e seu posterior emprego nos produtos desenvolvidos: Os mecanismos formais e informais; mecanismos externos e internos a empresa. Os mecanismos formais decorrem de atividades estruturadas e documentadas para a geração de inovações tecnológicas (pessoal qualificado e/ou contratos firmados entre a organização detentora dos meios para inovar e a organização que irá absorver e difundir a inovação). Os mecanismos informais para a inovação são provenientes da criatividade, experiência e qualificação de recursos humanos, ou de estímulos recebidos do meio externo, sem que haja alguma relação formal ou ato de natureza econômica.

Da mesma forma, Camila et al (2012), o desenvolvimento da capacidade de inovar não depende apenas de elementos internos das empresas, há sempre componentes dados pelo ambiente externo e decisões, que precisam ser tomados relativamente a ele. A capacidade de inovar depende também de condições objetivas dadas pela capacidade social de criar conhecimento do ambiente em que se insere a organização, incluindo a existência de competências específicas, de financiamento e de baixos custos de transação. Em outras palavras, da existência de sistemas de inovação bem constituídos (LUNDVALL et al, 2001).

\section{Aspectos Metodológicos}

O presente trabalho se caracteriza como estudo teórico descritivo qualitativo por meio de pesquisa bibliográfica. Quanto aos fins, esta pesquisa se classifica como pesquisa descritiva. Na visão de Vergara (2000), a pesquisa descritiva expõe características de determinada população ou de determinado fenômeno. Pode também estabelecer correlações entre variáveis e definir sua natureza. Gil (1991) menciona que o estudo teórico descritivo visa ir além da simples identificação da existência de relações entre variáveis, objetiva determinar a natureza dessa relação e proposição. Cita ainda a existência de pesquisas que, "embora definidas como descritivas a partir de seus objetivos, acabam servindo para pesquisas" (GIL, 1991).

Sobre a pesquisa bibliográfica, Vergara (2000) menciona que a pesquisa bibliográfica fornece instrumental para qualquer tipo de pesquisa, mas afirma também que "pode esgotar-se em si mesma" exigindo do pesquisador a possibilidade de emergir novos construtos teóricos.

\section{O Programa piloto brasileiro "Patentes Verdes"}

O programa brasileiro "Patentes Verdes" segue uma tendência internacional de priorizar a análise das tecnologias verdes. Desde 2009, uma série de países, especialmente os mais industrializados - incluindo 0 Reino Unido, Estados Unidos, Austrália, Coréia, Japão, Israel e Canadá - têm implementado medidas de acelerar a tramitação dos pedidos de patentes. Mais recentemente, economias emergentes, como o Brasil e a China também aderiram a esta tendência. RITCHER (2014) 


\section{A inovação como estratégia nas organizações sustentáveis: 0 programa piloto brasileiro para concessão das patentes verdes}

A primeira fase do programa piloto restringia-se aos pedidos a partir de 02/01/2011, na segunda fase, foram aceitos todos os pedidos que não foram examinados, cujas áreas de tecnologia estejam entre as aplicadas ao programa, inclusive modelos de utilidade. A partir desta fase, são aceitos pedidos via Tratado de Cooperação em Matéria de Patentes (PCT, na sigla em inglês). De acordo com o INPI, a concessão do pedido considerado "patente verde" ocorre em, no máximo, 2 anos, limitado a 500 exames (solicitações) ou até 16/04/2016 e a 15 reivindicações no total (até 3 reivindicações independentes).

Para qualificar-se, o pedido de patente será avaliado por uma comissão técnica do INPI e, por enquanto, serão somente admitidos pedidos relacionados a energias alternativas, transporte, conservação de energia, gerenciamento de resíduos e agricultura. Os requisitos para participar do projeto são os seguintes: o pedido deve ser uma Patente de Invenção (PI), o pedido deve ser nacional (residente ou não residente), os pedidos devem ter sido depositados no INPI a partir de 2 de janeiro de 2011 e por fim as solicitações devem incluir no máximo 15 reivindicações no total, das quais arranjadas em até três reivindicações independentes. A Resolução vigente PR $n^{\circ}$ 131/2014 do INPI, manteve a lista de tecnologias definida na resolução anterior do programa (PR122/2013), adstritas aos cinco eixos de tecnologias verdes para subscrição: energias alternativas, transporte, conservação de energia, gerenciamento de resíduos e agricultura.

O programa piloto Patentes Verdes tem como objetivo contribuir para as mudanças climáticas globais e visa a acelerar o exame dos pedidos de patentes relacionados a tecnologias voltadas para o meio ambiente. 0 campo de "tecnologia verde" engloba métodos, materiais e técnicas de geração de produtos que causam menos impacto ambiental. As tecnologias verdes, contempladas no Programa de Patentes Verdes são energia alternativa, transporte, conservação de energia, gerenciamento de resíduos e agricultura.

Conforme Barbieri et al (2010) é importante destacar abordagens que facilitem a introdução e difusão de tecnologias sustentáveis por meio de nichos tecnológicos, isto é, espaços protegidos que permitem uma série de experimentos relacionados com a evolução da tecnologia, práticas de uso e estruturas regulatórias. Exemplos de setores que se enquadrariam nessa abordagem: energia, biogás, sistemas de transporte públicos, produção de alimentos ecologicamente amigáveis. A premissa é que, se tais nichos forem construídos adequadamente, eles poderiam agir como base para mudanças maiores na sociedade em termos de desenvolvimento sustentável.

\section{Discussão e Considerações Finais}

Considerando-se a análise dos dados, à luz da revisão teórica e, a partir do objetivo proposto, percebeu-se que o Brasil desenvolveu instrumentos, diretrizes e estratégias para o desenvolvimento científico e tecnológico que evidenciaram avanços importantes por meio da Lei da novação. Portanto, é necessário a continuidade e aperfeiçoamentos de forma cada vez mais efetiva, para que se apresentem os resultados esperados focando nos pressupostos das ICTs e na flexibilidade da relação público e privada, atentando para o clima organizacional e mudança de cultura, aperfeiçoar a negociação no que tange a propriedade intelectual e também para o inventor independente.

Outro aspecto relevante é que a lei da inovação é fundamental na definição de diretrizes para o fomento de pesquisas científicas e tecnológicas, para o reconhecimento da inovação tecnológica como um dos fatores de desenvolvimento e de se inserir no sistema econômico globalizado e estabelece um cenário propício para os setores industriais e acadêmicos se interagirem de forma apropriada e por meio de regras de propriedade intelectual, envolvendo todos os atores da sociedade.

Sobretudo o Programa Piloto Patentes Verdes demonstra significativo potencial servindo de instrumento gerador da produção de tecnologias verdes, pois tem objetivo de reduzir o tempo de análise das solicitações de patentes verdes, gerando maiores incentivos a investimentos e inovações na área ambiental pela possibilidade de trazer retornos financeiros mais rápidos por meio da exploração comercial destas tecnologias 
Para isso, a busca sistemática por inovações radicais, ou seja, aquelas capazes de criar novos mercados e proporcionar rápida expansão produtiva e crescimento econômico, e por inovações incrementais, identificadas com processos de melhoria contínua, é fundamental para a sobrevivência das empresas.

A inovação é fundamental para a competitividade em custos e assim forte motivação para a produtividade industrial, também atua fortemente como barreira de entrada para a manutenção da liderança em setores estratégicos. No que tange a competitividade em produto, está muito relacionada à qualidade e desempenho para enfrentar o mercado internacional. Por fim, promove também o desenvolvimento econômico e social, à medida que reduz a dependência externa de produtos industrializados.

De acordo com o INPI, a Propriedade Intelectual é um tema de crescente importância para a economia brasileira e um canal de reconhecida inclusão na comunidade internacional. Aliado às patentes, é um instrumento essencial na difusão do conhecimento e na transformação do mesmo em benefícios sociais, influindo também na cooperação universidade-empresa, beneficiando ambas as partes e favorecendo o avanço tecnológico.

Neste sentido, entende-se que a sustentabilidade é um desafio complexo, e desenvolver estratégias sustentáveis amparadas pela Gestão da inovação proporcionando vantagem competitiva, além de estimular outras empresas com a noção de alcançar um mundo mais social e ambientalmente melhor, e notadamente no que tange os cinco eixos de tecnologias verdes do programa "Patentes Verdes", ou seja, energias alternativas, transporte, conservação de energia, gerenciamento de resíduos e agricultura.

Por fim, é importante salientar que devido à limitação do método escolhido, as informações levantadas não podem ser generalizadas pela própria natureza do tema. E, sobretudo como sugestão de pesquisas futuras pode-se como estudar a relação de programas de patentes verdes em outros países, estudos dos retornos financeiros e estudar demandas dos tipos de patentes (inovação e modelos de utilidade).

\section{Referências}

AGENDA 21. Disponível em http://www.onu.org.br/rio20/img/2012/01/agenda21.pdf. Acesso em 20/07/2015.

BARBIERI J.C; SIMANTOB, M.A. Organizações inovadoras sustentáveis: uma reflexão sobre o futuro das organizações. São Paulo, Atlas, 2007.

BARBIERI, J. C; VASCONCELOS, I. F. G.; TALES, A.; VASCONCELOS, F. C. Inovação e sustentabilidade: novos modelos e proposições. São Paulo, RAE, 2010.

CANONGIA, Claudia; SANTOS, Dalci M.; SANTOS, Marcio M.; ZACKIEWICZ, Mauro. Foresight, inteligência competitiva e gestão do conhecimento: instrumentos para a gestão da inovação. Gestão \& Produção. São Carlos, v. 11, n.2, mai/ago 2004.

CHESBROUGH, H.; VANHAVERBEKE, W; WEST, J. Open Innovation - Researching a New Paradigm, Oxford: Oxford University Press, 2006.

ONU - Organização das Nações Unidas. Disponível em: . Acesso em: 17/07/2015.

CONFERÊNCIA DAS NAÇÕES UNIDAS SOBRE DESENOLVIMENTO SUSTENTÁVEL RIO+20. O Futuro que Queremos. Disponível em http://www.mma.gov.br/port/conama/processos/61AA3835/O-Futuro-quequeremos1.pdf. Acesso em 21/06/2015.

CONSTITUIÇÃO DA REPÚBLICA FEDERATIVA DO BRASIL. CONSTITUIÇÃO DA REPÚBLICA FEDERATIVA DO BRASIL. Disponível em: ttp://www.planalto.gov.br/ccivil_03/constituicao/constituicao.htm. Acesso em: 23/06/2015.

ELKINGTON, J. Canibais com garfo e faca. São Paulo: Makron Books, 2001.

FERREL, O.C.; et al. Ética empresarial: dilemas, tomadas de decisões e casos. Rio de Janeiro: Reichmann \&Affonso. 2001. 


\section{A inovação como estratégia nas organizações sustentáveis: 0 programa piloto brasileiro para concessão das patentes verdes}

FONSECA, S. A.; KRUGLIANSKAS, I. Inovação em microempresas de setores tradicionais: estudos de casos em incubadoras brasileiras. In: Tecnologia e inovação: experiência de gestão na micro e pequena empresa. São Paulo: PGT/USP, 2002, p. 89-109.

FREEMAN, C. Technology and economic performance: lessons from Japan. Pinters Publishers. 1987.

KEINERT, T. M. M. Organizações Sustentáveis: utopias e inovações. Belo Horizonte: Fapemig, 2007.

GIL, A. C. Métodos e técnicas de pesquisa social. São Paulo, Atlas, 3. ed. 1991.

INPI. Das patentes verdes às marcas coletivas e IGs, INPI marca presença na Rio+20. http://www.inpi.gov.br/index.php?option=com_content\&view=article\&id=1188:daspatentes-verdes-as-marcascoletivas-e-igs-inpi-marca-presenca-nario20\&catid=50:slideshow\&ltemid=146. ACESSO EM 07.07.15

INPI. Cartilha da Propriedade Intelectual: PROJETO INVENTIVA. INPI - Instituto da Propriedade Industrial Rede de Tecnologia do Rio de Janeiro, 2002.

Organização para Cooperação e Desenvolvimento Econômico - OCDE. Manual de Oslo: proposta de diretrizes para coleta e interpretação de dados sobre inovação tecnológica. Rio de Janeiro: Finep, 2004.

LUNDVALL, B. A. et al. National systems of production, innovation and competence-building. In: NELSON AND WINTER DRUID SUMMER CONFERENCE, Aalborg Congress Center, Aalborg, Denmark, June, 2001.

MANUAL DE OLSO. Diretrizes para coleta e interpretação de dados sobre inovação. Terceira Edição, OECD, 2005. Disponível em < http://www.mct.gov.br/upd_blob/0026/26032.pdf > acessado em 08.05.2015

MASSAINI, S. A. Redes de Inovação : a Contribuição de Parcerias para o Desempenho Inovador de Empresas da Indústria Elétrica Eletrônica Brasileira, (11), 17-44. 2015

MINTZBERG, H.; AHLSTRAND, B.; LAMPEL, J. Strategy safari: a guided tour through the wilds of strategic management. New York: Free Press, 1998.

ONU - Organização das Nações Unidas. Disponível em: . Acesso em: 17/07/2015.

Organização para Cooperação e Desenvolvimento Econômico - OCDE. Manual de Oslo: proposta de diretrizes para coleta e interpretação de dados sobre inovação tecnológica. Rio de Janeiro: Finep, 2004.

RITCHER, F. A; As patentes verdes e o desenvolvimentno sustentável ,Revista Meio Ambiente e Sustentabilidade |vol. 6, n.3, p. 383 - 398 | jul - dez 2014

SCHUMPETER, J. A. Teoria do desenvolvimento econômico. São Paulo: Abril Cultural, 1982.

TEIGLAND, R. FEY, C.e BIRKINSHAW, J.. Knowledge dissemination in global R\&D operations. Management International Review, vol 40, 2000.

TIDD, J; BESSANT, J; PAVITT, K. Gestão da Inovação. 3 ed. Porto Alegre: Bookman, 2008.

VERGARA, Sylvia Constant. (2000). Projetos e relatórios de pesquisa em administração. 3.ed. São Paulo: Atlas WISNIEWSKI. M., G., \& BOLLMANN, H. A. . A Responsabilidade Socioambiental no contexto das relações entre mercado, estado e sociedade: CONTRIBUIÇÕES DA CONSTITUIÇÃO BRASILEIRA DE 1988, 17(1), 115-140. 2012

WORLD INTELCTUAL PROPERTY ORGANIZATION - WIPO. Disponível em: www.wipo.int acesso em: $21 / 06 / 2015$ 